\title{
Research on the Spatial Pattern and Influence Mechanism of Industrial Transformation and Development of Traditional Villages
}

\author{
Mingshui Lin ${ }^{1,2}$, Jingsong Jian ${ }^{1, *}, \mathrm{Hu} \mathrm{Yu}{ }^{3}$, Yanfang Zeng ${ }^{1,2, *}$ and Menglung Lin ${ }^{4}$ \\ 1 College of Tourism, Fujian Normal University, Fuzhou 350117, China; linms@fjnu.edu.cn \\ 2 The Higher Educational Key Laboratory for Smart Tourism of Fujian Province, Fuzhou 350117, China \\ 3 Institute of Geographic Sciences and Natural Resources Research, CAS, Beijing 100101, China; \\ yuhu@igsnrr.ac.cn \\ 4 Department of Tourism, Aletheia University, Taipei County 251, Taiwan; mllin1976@mail.au.edu.tw \\ * Correspondence: Jianjingsongg@163.com (J.J.); yanfang@fjnu.edu.cn (Y.Z.); Tel.: +86-0591-2286-8729 (Y.Z.)
}

Citation: Lin, M.; Jian, J.; Yu, H.; Zeng, Y.; Lin, M. Research on the Spatial Pattern and Influence Mechanism of Industrial Transformation and Development of Traditional Villages. Sustainability 2021, 13, 8898. https://doi.org/ $10.3390 /$ su13168898

Academic Editor: Vida Maliene

Received: 25 June 2021

Accepted: 5 August 2021

Published: 9 August 2021

Publisher's Note: MDPI stays neutral with regard to jurisdictional claims in published maps and institutional affiliations.

Copyright: (c) 2021 by the authors. Licensee MDPI, Basel, Switzerland. This article is an open access article distributed under the terms and conditions of the Creative Commons Attribution (CC BY) license (https:/ / creativecommons.org/licenses/by/ $4.0 /)$.
Abstract: Industrial transformation has been regarded as an important measure to promote traditional village revitalization. Research on the spatial pattern and influence mechanism of industrial transformation in traditional villages is urgently needed. In this context, this study takes the 211 national traditional villages in Fujian Province of China as research objects and uses GIS spatial analysis and geographical detectors to analyze the spatial pattern and influence mechanism of industrial transformation in traditional villages. The results show that: (1) the scale of traditional village industry presents the characteristics of wavy growth. High- and medium-density cluster areas were identified. (2) Traditional villages can be categorized into three types, not transformed, to be transformed and transformed villages. These three stages of transformation have different features of industry development and different dominant industries. (3) The core factors affecting the industrial transformation of traditional villages show obvious differences at different transformation stages and spatial differences in coastal and inland areas. Therefore, policies and measures should be customized to local conditions to improve the development quality of traditional villages and promote the industrial transformation and upgrading of traditional villages. This study improves the research on the transformation and development mechanism of traditional village industry from the perspective of industrial revitalization in theory and provides experience and models as reference for the revitalization of traditional village industry in practice.

Keywords: traditional villages; industrial transformation; influencing factors; rural revitalization; Fujian Province

\section{Introduction}

Industrial transformation and development refers to simultaneous coordination among and within industries in the process of adapting to social and economic development; it rationalizes resource allocation and flow within and among industries and steadily improves productivity [1]. Industrial transformation has been regarded as an important measure to promote traditional village revitalization, and increasing efforts have been made to discuss and evaluate the influence of industrial transformation in revitalizing traditional villages [2,3]. Studies have shown that industrial transformation in rural areas tends to boost rural economic development by developing rural industries, narrowing the gap between urban and rural areas, addressing unbalanced development caused by the duality between urban and rural areas, and promoting the integrated development of urban and rural areas [4-7]. The rural revitalization empirical experience in the EU, Australia, and other developed countries and regions has shown that industrial transformation has positive effects on promoting coordination in resource allocation and industrial specialization and consequently drives economic development [8-10]. The rural revitalization 
experience in Taiwan, China also shows that during the transformation from primary and secondary industries to tertiary industries, developing creative industry did not damage traditional cultural resources, but promoted the protection and inheritance of traditional cultural resources [11]. Therefore, protecting traditional values while promoting rural industrial revitalization is the primary task for the sustainable development of Chinese traditional villages [12,13].

Traditional villages are rich in history and culture. Industrial transformation of traditional villages should not only focus on cultivation and coordination of industries, but should also provide fertile ground for local folk custom and traditional culture. Thus, research on the paths and influence mechanism of industrial transformation in traditional villages is of great importance [14]. Li et al. [15] emphasized the equal exchange of urban-rural factors (e.g., labor, capital, and enterprise) and balanced allocation of public resources to promote urban-rural integration. Li et al. [16] and Fan [17] argued that during industrial transformation, the change of traditional village industry from primary to tertiary industry and the transformation from traditional space functions to multifunctions are conducive to coping with imbalanced development in the industrial transformation of traditional villages. Liu [18] pointed out that rural revitalization must be a multidimensional and multiperspective integration of green development and ecological environment protection. On such basis, explorations in the spatial pattern and influence mechanism of industrial transformation and development in traditional villages offer important technical support for the realization of rural revitalization. Researchers have conducted both theoretical discussion [19] and case studies exploring the development path of rural revitalization from theory and practice [20]. However, as rural industrial transformation in various areas is subject to varied social and economic factors under different influence mechanism and evolves in different paths, there is scant research focused on the spatial pattern, processes, and mechanisms of industrial transformation in traditional villages from the perspective of industrial revitalization. Little is understood about the mechanisms of industrial revitalization of traditional villages.

Responding to this research gap, this study aimed to explore the factors that influence industrial transformation of traditional villages and shed light on how to realize rural revitalization through industrial transformation and upgrading. This study adopts GIS spatial analysis and geographical detector analysis to examine the spatial pattern and influencing factors of industrial transformation and development for 211 national traditional villages in Fujian Province of China. It summarizes the experience and models of industrial revitalization in these villages, with the attempt to offer insights for decision making in promoting industrial revitalization of traditional villages.

\section{Literature Review}

\subsection{Spatial Pattern of Industrial Transformation}

Traditional villages are villages with particularly profound cultural heritage in rural areas. Research on the spatial pattern of industrial transformation has gradually become a hot spot for researchers. Studying the spatial pattern of industrial transformation is conducive to making use of complementary advantages of different villages so as to promote industrial transformation and development. Early scholars focused on large-scale samples of rural industrial transformation. Based on economic, social, and land use data, researchers studied the temporal and spatial differentiation of rural industries in typical regions by adopting the analytic hierarchy process method, entropy method, grey correlation method, BP model and Ward method, Dagum's Gini coefficient, and other research methods [21-23]. Long [24] identified three types of agricultural production transformation, namely, traditional farming, modern markets, and suburban leisure, and sorted out their overall characteristics, transformation problems, and transformation trends. Sun [25] found that rural industries in Nanjing Province of China had diversified characteristics and that their spatial distribution showed obvious regional differences. The development trend of industrial integration was obvious near the suburban areas and in the center of towns with 
distinct industrial diversity, while the industrial types in the outer suburbs were relatively single, mainly dominated by agricultural production. Some scholars also constructed index systems to divide rural areas into different types and explore the spatial distribution characteristics of different functional types of rural areas [26-28]. Bański et al. [29] studied the characteristics of economic transformation in Polish rural areas and divided them into five types, agriculture functional areas, functional homogeneous areas, nonagriculture functional areas, tourism and leisure functional areas, and forest coverage. Holmes [30] found that Cape York Peninsula in Australia was undergoing a multifunctional transition with Indigenous engagement, as a formerly flimsy productivist mode was readily displaced by more complex modes, with greater prominence given to consumption, protection, and Indigenous values. Recently, with the in-depth advancement of the rural revitalization strategy, research on the spatial pattern of traditional village industrial transformation has gradually transformed to meso- and microscale work with diversified research methods.

\subsection{Influence Mechanism of Industrial Transformation}

The influence mechanism of the industrial transformation of traditional villages is the antecedent of the current study on spatial pattern and a catalyst for the evolution of the spatial pattern in the future. Researchers have mainly studied the influence mechanism from the perspective of internal and external factors, push-pull factors, etc. Quantitative methods such as regression analysis are often used to quantify these factors. Luo [31] studied the different types of rural economy in the suburbs of Shanghai and analyzed the influencing factors such as location differences, natural conditions, historical basis, administrative behavior decision making, and transportation conditions. Song and Liu [32] analyzed the evolution of the multifunctional process of agricultural development from the plains in the suburbs of Beijing to the mountainous areas and found that this process was mainly affected by social development, economic development, and policy planning. Fang et al. [33] believed that because of differences in natural and unnatural capital, economic demand, market distance, labor supply, and infrastructure levels, China's rural areas were divided into different geographic types in the process of dynamic transformation. These methods can properly explain the mechanisms of the industrial transformation in plain areas, but for mountainous and hilly areas, they cannot reveal the influence of spatial factors such as topography and geomorphology. Methods using geographical detectors can make up for this defect. Since the development of this software, it has been widely used to reveal the influence mechanism of industrial transformation, but it has rarely been used to reveal the industrial transformation of traditional villages [34,35].

\subsection{Summary}

On the whole, research on industrial transformation of traditional villages has followed a progression from the macro- to the meso- and then to the microscale. However, despite the fruitful research on industrial transformation, there are still some areas that need to be studied in depth. First, in view of research perspective, most current research has studied industrial transformation from the perspectives of economics and sociology. There has been little analysis of the spatial characteristics and of the evolution of traditional village industries from the spatial perspective. Second, in terms of the research methods, as rural industry data is not easy to obtain, current research has mostly selected mathematical statistical methods by analyzing the income of local residents and local government policies and has seldom considered the impact of temporal and spatial characteristics on the transformation and development of traditional village industries. In addition, there is limited research on the spatial pattern of the industrial transformation of traditional villages in a certain province. 


\section{Methodology}

\subsection{Study Site}

Situated at the southeastern coast of China, Fujian faces Taiwan across the Straits and is one of the closest mainland provinces to Southeast Asia and Oceania (Figure 1). Fujian covers a land area of 121,400 square kilometers and a sea area of 136,000 square kilometers. Within provincial jurisdiction, there are nine municipal cities, including Fuzhou, Xiamen, Quanzhou, Zhangzhou, Putian, Longyan, Sanming, Nanping, and Ningde. Below municipal cities are districts under a municipality, counties, and county-level municipalities, with a total number of 85 . Below this level are villages, which are the lowest-level administrative divisions in China.

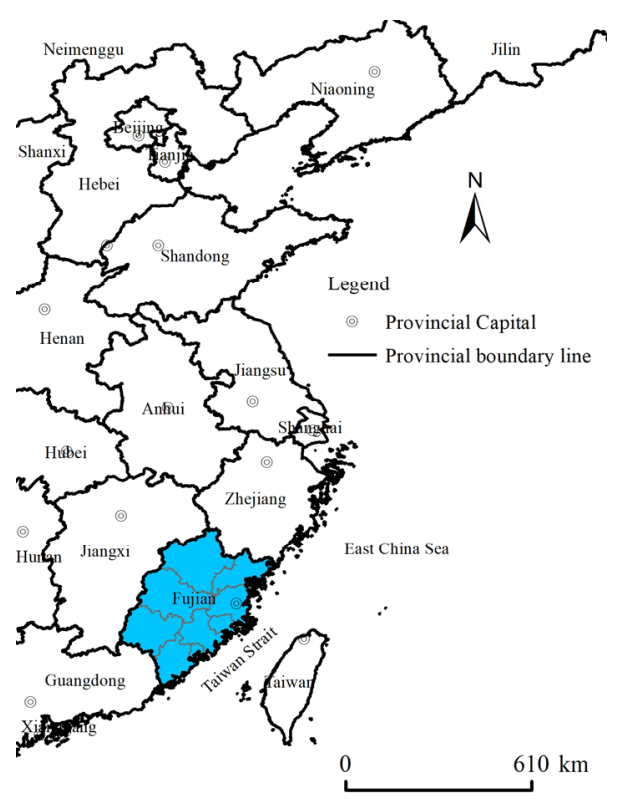

Figure 1. Location of the study area.

China has launched a program to protect the cultural heritage of the traditional villages since 2012. Villages with important conservation value are included in the list of "Chinese traditional villages". By 2019, a total of 6819 villages in five batches across the country were selected into the list. Fujian is closely tied with Taiwan through direct links of mail, air, and shipping services as well as trade and is one of the first movers in referring to experience of Taiwan to explore pilot rural start-ups and transformations [36]. This study takes the 211 national traditional villages in Fujian Province as research objects to study the spatial pattern and influence mechanism of industrial transformation.

\subsection{Data Collection}

The statistical yearbooks do not have data on the industrial sectors of traditional villages, so it is impossible to directly obtain the industry statistics data of traditional villages. However, the research team found that the industrial characteristics of traditional villages can be indirectly reflected by the quantity and type of enterprises set up in the villages. For instance, traditional villages with well-developed primary industry tend to establish rural cooperatives to encourage agricultural cultivation. Villages with welldeveloped secondary industries mostly set up rural enterprises to carry out standardized and large-scale production. Villages with well-developed tertiary industry usually set up wholesale and retail enterprises as well as tourism and service companies to carry out trade and tourism activities. Therefore, in the absence of direct statistical data, the number of traditional village enterprises can indirectly reflect the overall scale and strength of rural industries [37]. 
According to the Regulation on the Classification of Three Industries in the Industrial Classification for National Economic Activities (GB/T4754-2011) released by the National Bureau of Statistics, the research team searched enterprise data with registered addresses in 211 traditional villages, including enterprise type, registered capital, enterprise nature, date of establishment, current operating status, etc. via Qcc.com, TianYanCha.com, and the Fujian enterprise credit information publicity system. The data about enterprises with registered addresses were acquired from the Fujian Provincial Enterprise Credit Database, as shown in Table 1. Informal enterprises that were not registered in the Database were not included in this study. The acquired data was standardized into the industrial database on the traditional villages in Fujian.

Table 1. The number of traditional villages and enterprises.

\begin{tabular}{|c|c|c|c|c|c|c|}
\hline Figure & Cities & $\begin{array}{l}\text { Traditional } \\
\text { Villages }\end{array}$ & Enterprises & $\begin{array}{l}\text { Primary Industry } \\
\text { Enterprises }\end{array}$ & $\begin{array}{l}\text { Secondary Industry } \\
\text { Enterprises }\end{array}$ & $\begin{array}{c}\text { Tertiary Industry } \\
\text { Enterprises }\end{array}$ \\
\hline \multirow{7}{*}{ Coastal cities } & Fuzhou & 19 & 1323 & 49 & 135 & 1139 \\
\hline & Ningde & 55 & 5420 & 1128 & 743 & 3549 \\
\hline & Putian & 1 & 62 & 7 & 4 & 51 \\
\hline & Quanzhou & 18 & 3836 & 244 & 1303 & 2289 \\
\hline & Zhangzhou & 24 & 3155 & 475 & 341 & 2339 \\
\hline & Total 1 & 117 & 13,796 & 1903 & 2526 & 9367 \\
\hline & Longyan & 32 & 4128 & 49 & 448 & 3631 \\
\hline \multirow{3}{*}{ Inland cities } & Sanming & 30 & 1105 & 312 & 188 & 605 \\
\hline & Nanping & 32 & 2422 & 596 & 471 & 1355 \\
\hline & Total 2 & 94 & 7655 & 957 & 1107 & 5591 \\
\hline $\begin{array}{l}\text { Coastal and } \\
\text { inland cities }\end{array}$ & Total & 211 & 21,451 & 2860 & 3633 & 14,958 \\
\hline
\end{tabular}

\subsection{Methods}

The methods used in this study include GIS spatial analysis, cluster analysis, and geographical detector analysis. GIS spatial analysis was used to analyze the spatial distribution of industrial transformation in various stages of traditional villages and shed light on the differences in industrial transformation in different regions. Cluster analysis was used to classify traditional villages based on dominant industries and analyze the changes in the dominant industries of the villages at each stage. Geographical detector analysis was used to extract major influencing factors on transformation and qualitatively evaluate these factors.

\subsubsection{GIS Spatial Analysis}

With ArcGIS adopted, the study used a thematic map to analyze the process of industrial transformation in the traditional villages in different periods of time and used kernel density to calculate the density of dominant industries of the traditional villages via the following formula:

$$
P\left(X_{i}\right)=\frac{1}{n h} \sum^{n} k\left(\frac{X_{i}-X_{j}}{h}\right)
$$

where $k$ refers to a kernel function, $h$ refers to bandwidth, and $x_{i}-x_{j}$ refers to distance from measuring point $x_{i}$ to sample point $x_{j}$.

\subsubsection{Geographical Detector Analysis}

A geographical detector is a statistical method for exploring the laws of spatially stratified heterogeneity of data and analyzing the driving factors. This method can effectively explain the influence mechanism of industrial transformation in traditional villages, as the detector can not only detect a spatial heterogeneity value, but can identify the major influencing factors and to what extent these factors explain the spatial heterogeneity. In general, the geographical detector contained four formulas: the factor detector, the interac- 
tion detector, the risk detector, and the ecological detector. The factor detector was used to detect the spatial differentiation of industrial transformation of traditional villages and to determine the proportions of this spatial distribution that can be explained by different factors. It was obtained by comparing the sum of the variance of the subareas in a region and the variance of the total region, which can each be measured by the $q$ value:

$$
q=1-\frac{\sum_{h=1}^{L} N_{h} \sigma_{h}^{2}}{N \sigma^{2}}=1-\frac{S S W}{S S T} S S W=\sum_{h=1}^{l} N_{h} \sigma_{h}^{2}, S S T=N \sigma^{2}
$$

where $h(h=1, \ldots, L)$ indicates the stratified status of influencing factor $\mathrm{X} ; N$ is the number of units in the whole region; $N_{h}$ is the number of units in stratum $h ; \sigma_{h}^{2}$ is the variance of industrial transformation in stratum $h$; and $\sigma^{2}$ is the variance in the whole region. SSW and SST represent the sum of the variance of the subareas and the variance of the total region, respectively. The $q$ value indicates that influencing factors could explain $100 \times q \%$ of the spatial distribution of industrial transformation. The $q$ value has a range of $(0,1)$. Higher values of $q$ mean greater influence of subregional factors on industrial transformation.

Some studies indicate that natural factors are not main drivers for the industrial transformation of traditional villages in the short term, as natural factors are relatively stable. It is the human factors (e.g., economic and social factors) that are comparatively more active $[38,39]$ and have major effects on the industrial transformation. On such basis, this study mainly focused on human factors.

Previous studies have shown that the industrial transformation of traditional villages is mainly subject to economic and social factors [40-42]. Regional economic development level (GDP growth) and size of consumer market (per capita GDP and total retail sales of consumer goods) were selected as economic influencing factors for industrial transformation. The level of industrial structural upgrading is closely related with economic development level [43], as economic environment directly determines the development prospect of each industry and ensures continuous growth of per capita GDP and further enhances consumer demand [44]. Investment (regional direct investment), traffic and transport (highway mileage), and policy environment (scientific and technological expenditure) were chosen as social influencing factors for industrial transformation. Investment directly affects industrial structure. In coastal areas such as Fujian, industrial development is subject to the inevitable influence of location; thus, traffic accessibility is critical for economic exchanges [45]. Government has been playing a major role in industrial structural adjustment for economic transformation and development. The influence of technological factors on industrial transformation is also self-evident. Therefore, the more effective policies on fiscal expenditure on science and technology work to the greater advantage of industrial structural upgrading [46]. As industrial transformation and upgrading refer to the change from labor-intensive to technology- and innovation-intensive industries and is fundamentally a process of optimizing and upgrading the expertise, capabilities, and qualities of professionals [47], scientific and technological expenditure plays a vital role in the process which offers enormous incentives for the transformation. This paper designates the industrial transformation index as $\mathrm{Y}$ and six factors including GDP growth $(X 1)$, regional direct investment $(X 2)$, per capita GDP $(X 3)$, highway mileage $(X 4)$, scientific and technological expenditure (X5), and total retail sales of consumer goods (X6) as $X$ to detect the influencing effect of each factor on spatial pattern of rural industrial transformation. Data on the aforementioned regional factors was mainly sourced from China Statistical Yearbooks.

\subsection{Industrial Transformation Index of Traditional Villages}

3.4.1. Construction of the Evaluation Index System

An evaluation index system on industrial transformation of traditional villages was constructed to reflect the transformation process of enterprises in the villages participating in rural industrial revitalization. The enterprises were categorized by industrial attribute to 
indicate the size of each industry in the villages. Given the wide gap in registered capital among primary, secondary, and tertiary industry, industrial attribute and registered capital were selected $[37,48]$ as the two dimensions of the industrial transformation index. The industrial attribute stands for which industry an enterprise belongs to, such as primary industry, secondary industry, or tertiary industry. Registered capital stands for total capital registered with administrative authorities when setting up an enterprise as a legal person, reflecting strength of the enterprise in expansion.

\subsubsection{Standardization of the Evaluation Indexes}

The evaluation indexes were standardized to overcome differences in their dimensions and physical meanings and their parameter incomparability. The range method was used to assign value to the relationship between the evaluation indexes and industrial transformation. A greater positive correlation means higher transformation capability, while a greater negative correlation means lower transformation capability.

Previous research on transformation of traditional village enterprises indicates that with respect to investment, enterprises of larger size tend to have greater strength and naturally become the focus of attention in local areas. They usually pose an obvious radiating effect and are more helpful for local industrial transformation [49]. Therefore, traditional village enterprises of superlarge size and with higher registered capital are more conducive to the transformation of traditional village industry.

Stratified value assignment was adopted to evaluate business type and registered capital. First, according to the Regulation on the Classification of Three Industries in the Industrial Classification for National Economic Activities (GB/T4754-2011) released by the National Bureau of Statistics, all the enterprises in traditional villages are categorized into primary, secondary, and tertiary industry. The total number of enterprises in the primary, secondary, and tertiary industries were obtained (as shown in Table 1). Second, natural breaks classification was used to standardize registered capital into five classes and assign those classes values of 2, 4,6,8, and 10, respectively [47,50], as shown in Table 2. Finally, the number of enterprises was multiplied by the accumulated score of each enterprise's registered capital after standardization, and the industrial transformation index of each village at each stage was obtained.

Table 2. Standardized value assignment.

\begin{tabular}{cccccc}
\hline \multirow{2}{*}{ Index } & \multicolumn{5}{c}{ Standardized Value Assignment } \\
\cline { 2 - 6 } & $\mathbf{2}$ & $\mathbf{4}$ & $\mathbf{6}$ & $\mathbf{8}$ & $\mathbf{1 0}$ \\
\hline Registered capital (RMB10,000) & $<500$ & $500-2200$ & $2200-5000$ & $5000-8600$ & $>8600$ \\
\hline
\end{tabular}

\subsubsection{Classification of Dominant Industry}

Changes with regional industrial structure can not only represent efficiency of resource utilization and application of industrial technologies, but reflect employment types in the labor force and spatial scope of the labor force's daily activities. For instance, primary industry-dominant areas focus on the innovation of agricultural technology and the improvement of land fertility. Local residents' production and daily-life activities are carried out around agricultural land [51]. The focus of secondary industry areas is on the renewal of mechanized production technology and the reduction of raw material resource costs, and local residents' production and daily-life activities center on industrial land [52]. Tertiary industry-dominant areas are dedicated to the popularization of information technologies and improvement of human resources, and local residents' production and daily-life activities unfold around land for cultural, tourism, trade, and service purposes [53].

Cluster analysis was adopted to identify the types of dominant industries in traditional villages in Fujian [54]. First, on the basis of the transformation evaluation index system, a unified K-value cluster analysis was performed to analyze the data on industrial structure of the villages in different years. Second, according to the proportions of various indus- 
tries, the traditional villages in Fujian were categorized into primary industry-dominant, secondary industry-dominant, tertiary industry-dominant, and balance-developed villages.

\section{Results and Discussion}

\subsection{Spatial Characteristics of Traditional Village Enterprise}

\subsubsection{Spatial-Temporal Pattern}

Temporally, the growth curve of the number of traditional village enterprises in Fujian presents three turning points in a growing trend, and so is divided into three growth stages as shown in Figure 2. To be specific, during 1980-2000, the number of enterprises grew slowly, with 66 set up annually on average, and reached the first peak in 2000, increasing by 255 annually. During 2001-2009, enterprises grew at a medium pace, with 524 established annually on average. After the Decision of the Central Committee of the Communist Party of China on Several Major Issues on Promoting Rural Reform and Development was released in 2008, growth came to a second peak in 2009 with 1058 enterprises established annually. During 2010-2020, enterprises grew rapidly, with 1708 incorporated annually on average. After the report of the 19th National Congress of the CPC proposed the strategy of rural revitalization and the No.1 central document identified pursuit of a Chinese path to socialist rural revitalization, growth experienced a third peak in 2019, with 2920 enterprises established annually.

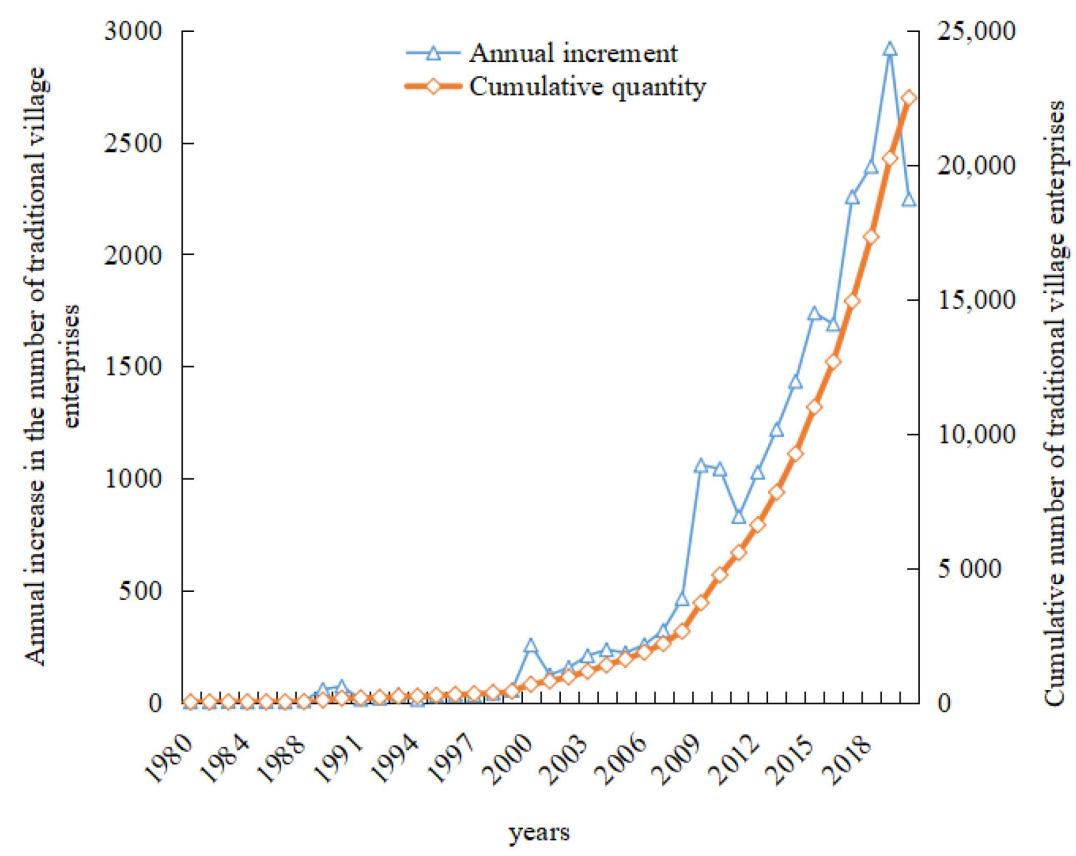

Figure 2. The number of traditional village enterprises from 1980 to 2020.

Spatially, traditional village enterprises in Fujian are mainly distributed in coastal areas, as demonstrated in Figure 3. About $62.7 \%$ of enterprises gathered in traditional villages in coastal areas, with high-density cluster areas formed in Pingnan and Zhouning counties of Ningde, Dehua County of Quanzhou, and Pinghe County of Zhangzhou. Medium-density cluster areas formed in Yongtai County of Fuzhou, Jiaocheng District of Ningde, and Jinjiang City of Quanzhou. For example, Sanban Village in Dehua County of Quanzhou owns 1721 enterprises. Back in 1984, the village set up its first nonmetallic manufacturing enterprise, the Dehua Sanban Bamboo and Wood Plant. By 2000, a total of 33 enterprises were set up, among which 24 were engaged in secondary industry. In 2009,136 enterprises were established in total, including 13 in primary industry with a total registered capital of RMB4.46 million, 55 in secondary industry with a total registered capital of RMB46.303 million, and 68 in tertiary industry with a total registered capital of 
RMB11.835 million. The balanced development among primary, secondary, and tertiary industries is the manifestation of the gradual transformation in Sanban Village.

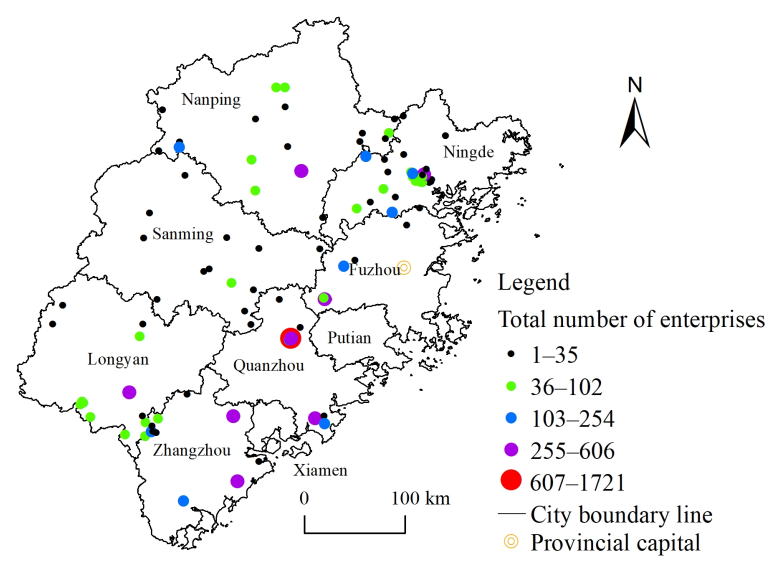

Figure 3. Distribution of the total number of enterprises in traditional villages.

\subsubsection{Spatial Patterns}

(1) Spatial Pattern by Industrial Type

Cluster analysis was used to classify traditional villages based on dominant industries into four types, namely primary industry-dominant, secondary industry-dominant, tertiary industry-dominant, and balance-developed villages, as presented in Figure 4. From the Decision of the Central Committee of the Communist Party of China on Several Major Issues on Promoting Rural Reform and Development issued in 2008 to the report of the 19th National Congress of the CPC that proposed the strategy of rural revitalization in 2017, differences in industrial structure of local traditional villages gradually narrowed. The balanced development among the primary, secondary, and tertiary industries in 2000 was transformed into secondary- and tertiary-dominant industry in 2020. During 1980-2000, many villages in Fujian were supported by no industry at all or a weak tertiary industry composed of a few retail businesses, and such villages were mainly located in western Ningde and inland areas. During 2001-2009, traditional villages started to see dominant industries and presented differences in industrial structure. Primary industry-dominant villages included Lian Village and Baixi Village in Ninde, Fuquan Village in Quanzhou, and Xiaojiashan Village in Sanming. Secondary industry-dominant villages included Yuezhou Village in Fuzhou, Shiqiao Village in Ningde, Zengban Village in Quanzhou, Yantai Village in Longyan, and Zhengwei Village in Nanping. Tertiary industry-dominant villages were Daonan Village in Fuzhou, Shanyang Village in Ningde, Jichuan Village in Putian, Zhongxin Village in Longyan, and Yangyuan Village in Nanping. During 2010-2020, though tertiary industry became dominant in the traditional villages in general, the villages in coastal areas saw a larger number of industries of larger size and richer variety, while those in inland areas were supported by a smaller number of enterprises basically all in retail. Coastal villages included Daonan Village in Fuzhou, Shanyang Village and Puyuan Village in Ningde, Sanban Village in Quanzhou, and Guihou Village in Zhangzhou. Inland villages included Zhixi Village, Zhongxin Village, and Lingyan Village in Longyan and Jiyang Village in Sanming. 


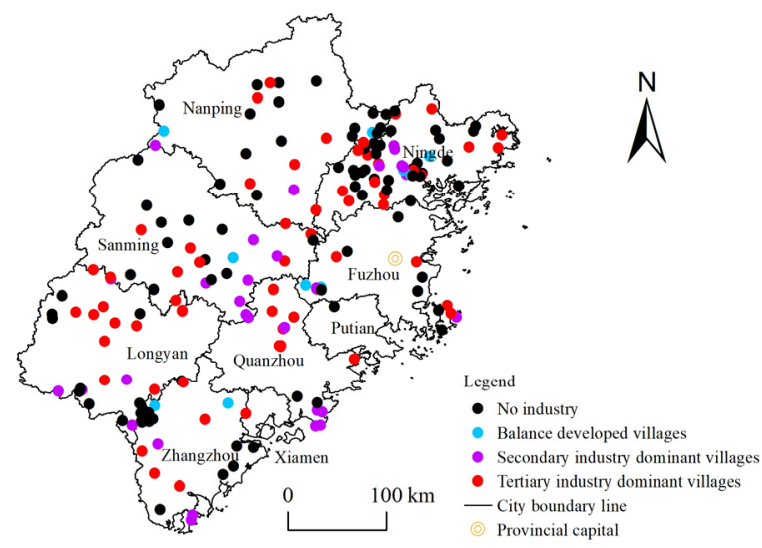

(a) 1980-2000.

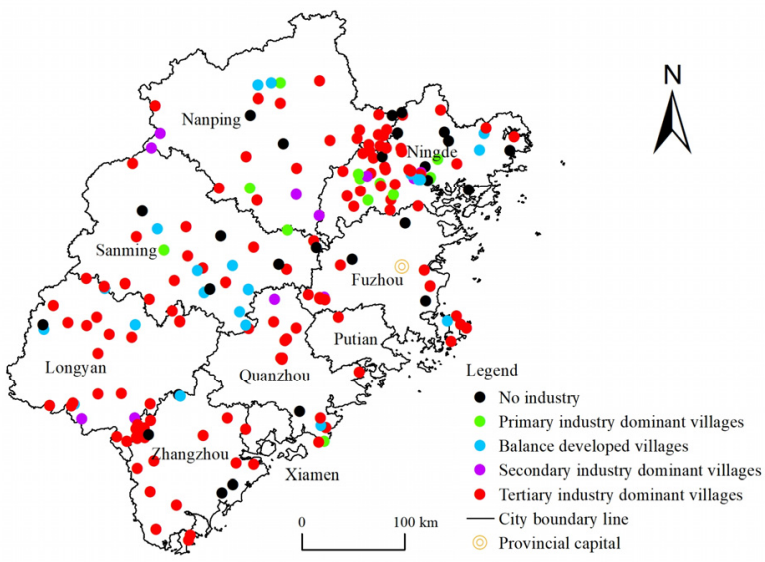

(b) 2001-2009.

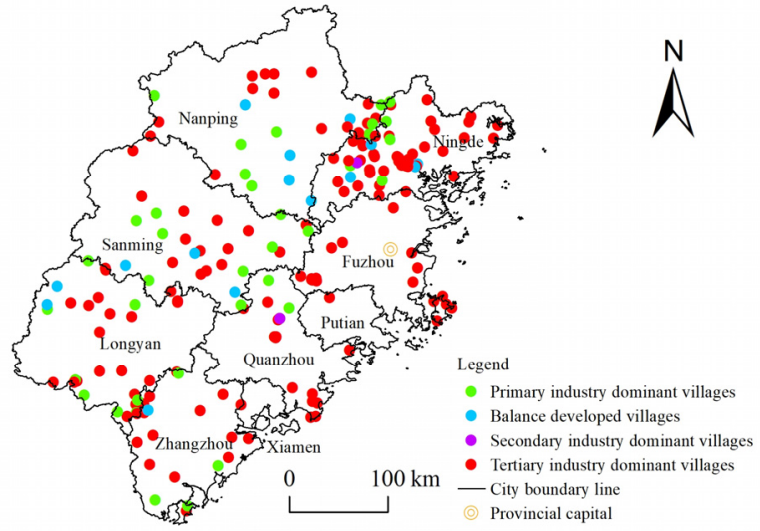

(c) 2010-2020.

Figure 4. Transformation of traditional village industry.

(2) Spatial Pattern by Enterprise Registered Capital

The average size of traditional village enterprises in Fujian Province is not large, with large-size rural enterprises mainly distributed in Fuzhou and Quanzhou, as shown in Figure 5. The total registered capital of traditional village enterprises is RMB28,212.64 million, and the average registered capital is RMB133.71 million. Regarding date of establishment, out of the 21 traditional villages with level- 4 and level-5 registered capital, 20 had a cumulative registered capital of over RMB388.03 million after 2009, while 18 saw the birth of no rural enterprises of high-level size prior to 2009. This is subject to the influence of the 
national rural revitalization policy and closely related with Fujian's regional development strategy of rural industrial transformation and upgrading.

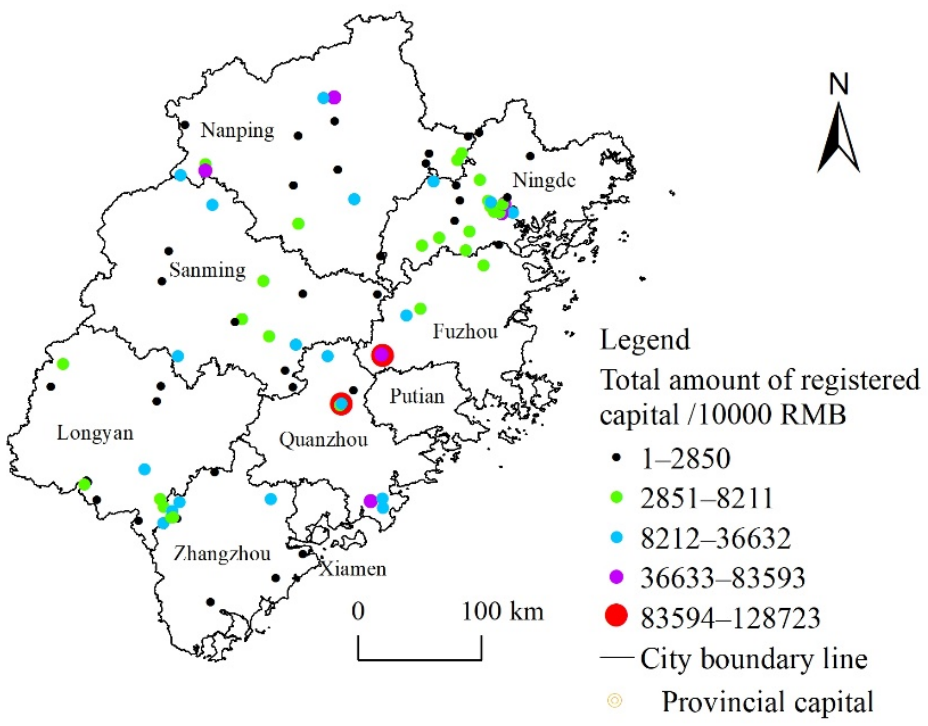

Figure 5. Spatial pattern of registered capital of traditional village enterprises.

With respect to spatial pattern, traditional village enterprises with high-level registered capital are mainly distributed in coastal areas. There are only four villages with level-5 registered capital, which totals RMB5600.6437 million and accounts for $19.8 \%$ of the total. They are distributed in Daonan Village in Fuzhou and Nanxun Village in Quanzhou, and their leading industry is tertiary industry. There are only 17 traditional villages with level-4 registered capital, which totals RMB10,159.1775 million and accounts for 36\% of the total, and they are distributed in Fuzhou. Forty-eight traditional villages have level-3 registered capital, which amounts to RMB8770.9108 million and accounts for 31\% of the total. Fifty-two traditional villages have level-2 registered capital, which totals RMB2514.3822 million and accounts for $8.9 \%$ of the total. There are 90 traditional villages with level-1 registered capital of RMB1085.4115 million in total, 3.8\% of the total. Traditional villages with level-1 and level-2 registered capital account for $69 \%$ in number, while their registered capital takes up a share of only $12.7 \%$ and is averaged at RMB25.3506 million, signaling a polarizing trend among the traditional village enterprises in Fujian in terms of enterprise size.

\subsection{Types of Industrial Transformation of Traditional Villages \\ Analysis of the Industrial Transformation Changes}

In order to further analyze the industrial transformation of traditional villages in Fujian, a unified K-value cluster analysis was performed to identify different types of transformation. Industrial transformation is conducive to the upgrading of industrial structure. The process of industrial structure upgrading is moving from primary industryand secondary industry-dominant to the balanced development of three industries. Thus, based on the industrial structure data of traditional villages from different years, traditional villages were categorized into three types, namely, not transformed, to be transformed, and transformed. The result is presented in Table 3. 
Table 3. Industrial transformation types of traditional villages in Fujian Province.

\begin{tabular}{cccc}
\hline & Not Transformed & To Be Transformed & Transformed \\
\hline Number of villages & 142 & 33 & 18 \\
Location & $\begin{array}{c}\text { Distributed in central and } \\
\text { western Ningde } \\
\text { and Sanming }\end{array}$ & $\begin{array}{c}\text { Mainly concentrated in } \\
\text { southwestern Fuzhou, } \\
\text { northwestern Quanzhou, and } \\
\text { western Zhangzhou }\end{array}$ & $\begin{array}{c}\text { Distributed in coastal cities, such as } \\
\text { Fuanzhou, and Ningde, and } \\
\text { the inland city Longyan }\end{array}$ \\
\hline
\end{tabular}

\section{(1) Not Transformed Villages}

The 142 villages that fall into this category are mostly distributed in inland areas, mainly in central and western Ningde and Sanming. They started late in development at a slow pace and are mainly engaged in tertiary industry, especially retail services. During 1980-2009, many traditional villages in this category incubated no enterprises or only a few enterprises in the tertiary industry and especially retail. Unlike what may be expected from industrial transformation in urban areas, traditional villages did not directly choose primary or secondary industry to drive industrial development at their early development stage but pursued tertiary industry such as retail as their first choice for developing enterprises and regional economy [55]. On the one hand, retail requires only a small investment and easily meets daily-life demands of villagers. On the other hand, villagers have limited social demands and could basically achieve self-sufficiency. However, tertiary industry such as retail generated little economic benefit, and so industrial transformation did not progress. Thus, this type of village is categorized as not transformed.

\section{(2) To-Be-Transformed Villages}

This category covers 33 villages, which are mainly concentrated in southwestern Fuzhou, northwestern Quanzhou, and western Zhangzhou. Local enterprises grow rapidly in quantity, but local industries are not complete in type and not distinct in leading industry. Currently, the majority of local villages remain to be transformed, and such traditional villages are in exploration for industrial development. Different types of villages show different characteristics of transformation and development.

First, some villages develop primary industry as their leading industry while accessory industries such as processing and manufacturing, agriculture, forestry, animal husbandry, and fishery quickly develop. Fishery is an important industry in most coastal traditional villages, while agriculture and forestry are main industries in inland traditional villages. Villagers rely on their own resource endowments to develop primary industry and then drive secondary and tertiary industries to develop rapidly, but the industrial structure has not been dramatically changed. The village industry remains to be transformed.

Second, some villages develop secondary industry as their leading industry. These villages have experienced the changing process of secondary industry developing as the leading one at the early stage; primary, secondary, and tertiary industries developing in relative balance at the middle stage; and then secondary industry leading later. This is a dilemma faced by most to-be-transformed villages. At the early stage, these villages benefited from urban industrialization and seized the opportunity of processing and manufacturing development to promote the growth of the village economy and primary and tertiary industries; at the middle stage, due to labor force drainage and hollowing out, the secondary industry quickly declined; later, as stimulated by the rural revitalization strategy, secondary industry managed to resume fast development, since processing and manufacturing are important drivers of rural industrial revitalization.

Villages in this category enjoy relatively strong economic strength, but due to their own limits or policy reasons, they have not realized industrial transformation and remain at the stage of development and exploration. They are therefore defined as to-be-transformed villages. 


\section{(3) Transformed Villages}

Only 18 villages fall into this category, which are distributed in coastal cities such as Fuzhou, Quanzhou, and Ningde and concentrated in the inland city of Longyan. For villages of this category, secondary industry is the main driver of development, and processing and manufacturing industries are important channels of industrial transformation. Villages of this type generally present a complete process of transformation. They usually established secondary industry as the leading industry at the early stage and achieved relatively balanced development of primary, secondary, and tertiary industries at the middle stage. Tertiary industry then showed an increasing trend and became the dominant industry at the later stage, with a large number of large-size enterprises. Meanwhile, traditional villages of this type usually become the growth pole of rural development within their counties and have a strong driving and radiating effect on neighboring villages. As a result, the neighboring villages move rapidly in industrial development and transformation and get ahead of other villages in realizing industrial transformation. Typical villages of this category are Daonan Village in Fuzhou, Puyuan Village in Ningde, Sanban Village and Nanxun Village in Quanzhou, and Zhongxin Village and Lingyan Village in Longyan.

\subsection{Influence Mechanism of Industrial Transformation of Traditional Villages}

In order to explore the influence mechanism of industrial transformation of traditional villages from a micro perspective, the factor detector in the geographical detector was used to conduct the analysis. Traditional villages are unevenly distributed in different counties, and the development of traditional villages is strongly influenced by local county social and economic factors. Therefore, this article designated the industrial transformation index of traditional villages in each county as $\mathrm{Y}$. Thus, $\mathrm{Y}$ is the accumulated value of the industrial transformation index of each village (calculated by the index constructed in Section 3.4.2) within the county. Six influencing factors were selected to quantitatively evaluate the industrial transformation, including GDP growth (X1), regional direct investment $(\mathrm{X} 2)$, per capita GDP (X3), highway mileage (X4), scientific and technological expenditure (X5), and total retail sales of consumer goods (X6). The data of the six influencing factors were also chosen at the county level based on two reasons. On the one hand, the industrial transformation of a traditional village is affected by the social and economic factors of the county in which the village is located. On the other hand, through comparative analysis of the industrial transformation of traditional villages in each county, it is helpful to propose customized rural revitalization policies for traditional villages.

To further reveal the spatial characteristics of the detection factors of industrial transformation, the natural discontinuity method in ArcGIS was used to reclassify the raster data of the $X$ variables to obtain the classified data. The classification results were graded, colored, and overlapped with the industrial transformation distribution map, as shown in Figure 6. After X1-X6 were discretized into discrete data, the relationships between $Y$ and X1-X6 were established by the geodetector to calculate the $q$ value of each factor's influence on the spatial distribution of industrial transformation in each county, as shown in Table 4 . The core factors affecting the industrial transformation of traditional villages showed obvious differences at different transformation stages and spatial differences in coastal and inland areas.

\subsubsection{Difference in Influencing Factors for Different Transformation Types}

The traditional villages were categorized as not transformed, to-be-transformed, and transformed villages. The three transformation types presented obvious differences in influencing factors.

Not transformed traditional villages were mainly subject to the influence of economic development level X1 (GDP growth) and investment X2 (regional direct investment), as indicated in Figure 6. According to analysis of the $q$ value between industrial transformation and each factor with the geographical detector, X1 (0.58) and X2 (0.53) of Nan'an City and X1 (0.51) and X2 (0.53) of Fuqing City were affected by X1 and X2 in the most profound way. 
At the stage when industry is not transformed in traditional villages, as there are only a few enterprises and retail is the main industry, the local economic development level poses direct effects on industrial development. Moreover, greater investment by government drives industrial transformation and development more noticeably.

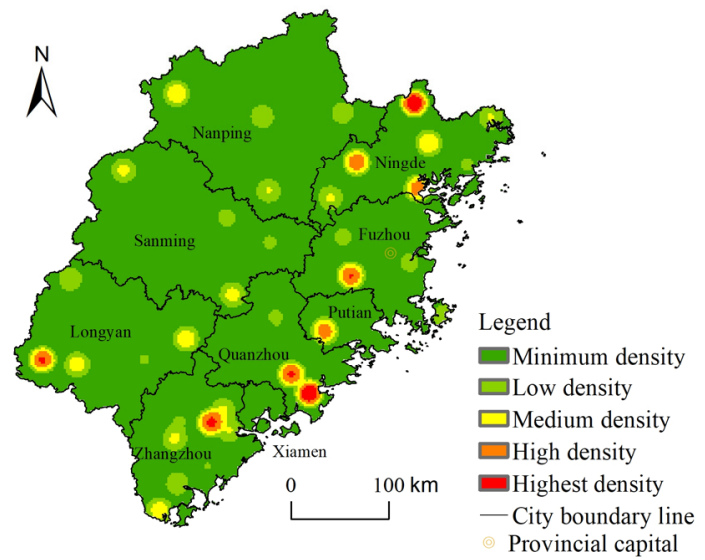

(a) Industrial transformation value $(\mathrm{Y})$

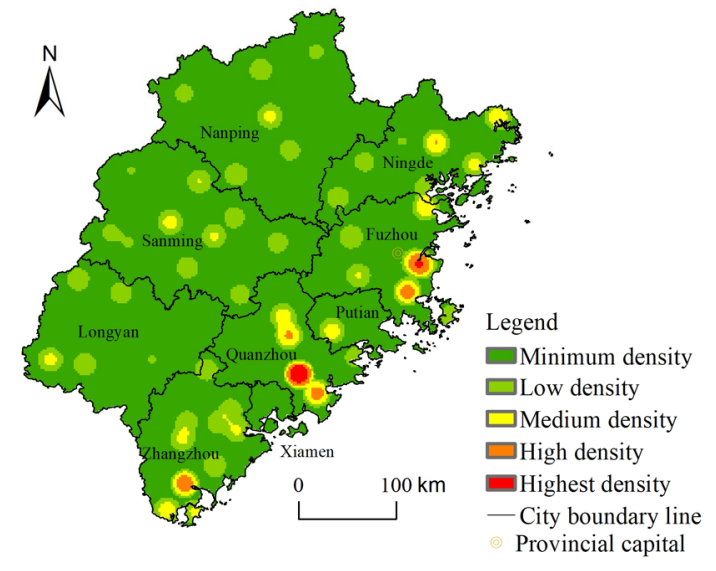

(b) GDP growth (X1)

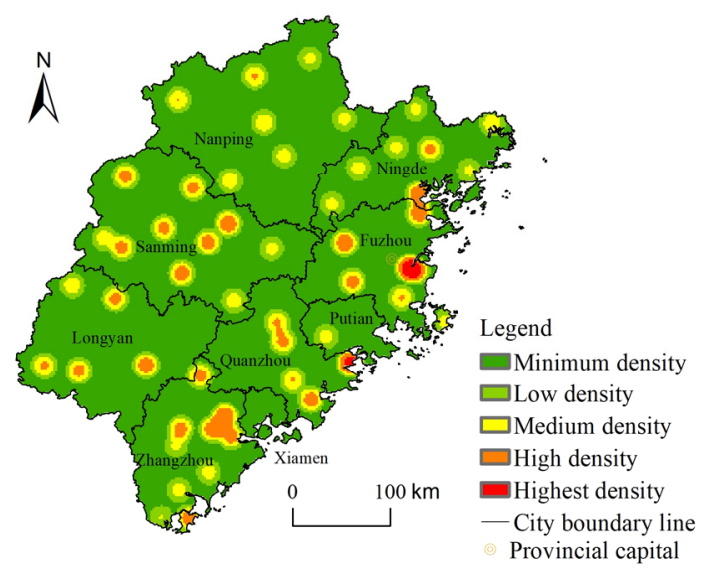

(d) Per capita GDP (X3)

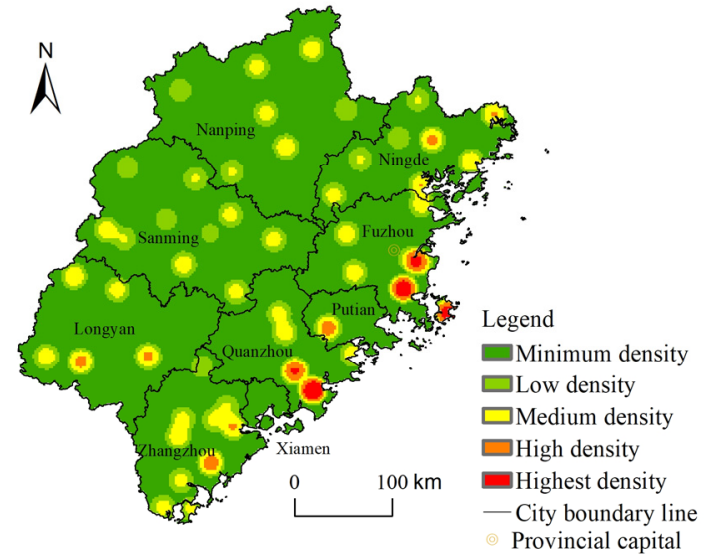

(c) Regional direct investment (X2)

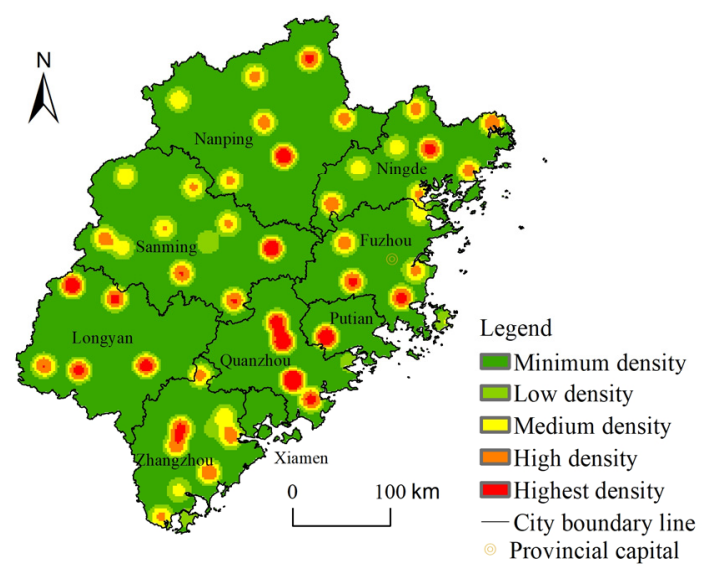

(e) Highway mileage (X4)

Figure 6. Cont. 


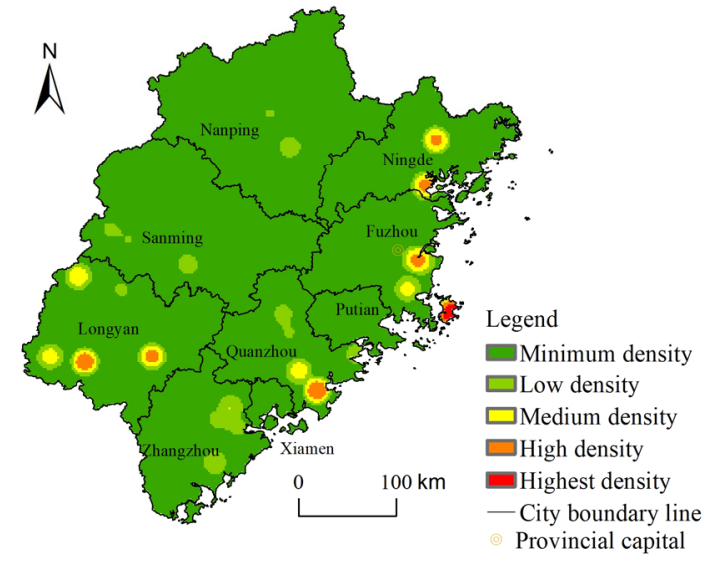

(f) Scientific and technological expenditure (X5)

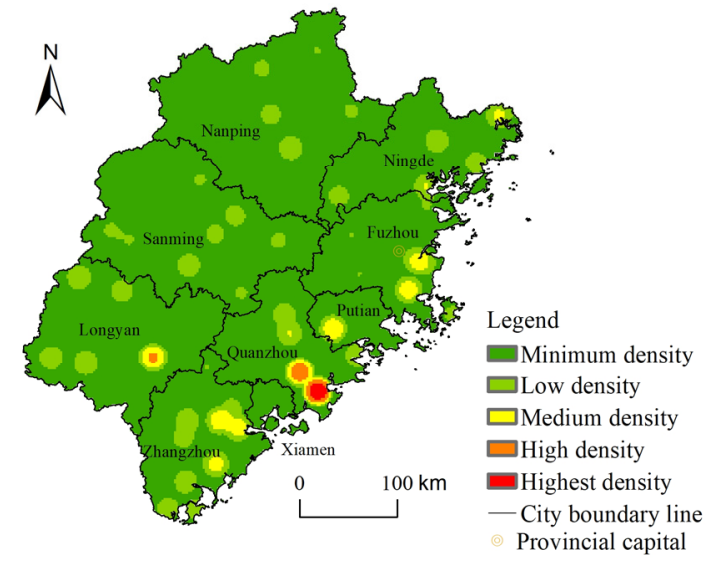

(g) Total retail sales of consumer goods (X6)

Figure 6. Industrial transformation values of traditional villages and their influencing factors.

Table 4. Analysis on geographical detection of various factors in different types of village.

\begin{tabular}{|c|c|c|c|c|c|c|c|c|c|c|c|c|c|c|c|}
\hline $\begin{array}{l}\text { Coastal } \\
\text { Municipal } \\
\text { Cities }\end{array}$ & $\begin{array}{c}\text { Districts/Counties/ } \\
\text { County-Level } \\
\text { Cities }\end{array}$ & $\mathrm{X} 1$ & $\mathrm{X} 2$ & X3 & $\mathrm{X} 4$ & X5 & X6 & $\begin{array}{l}\text { Inland Mu- } \\
\text { nicipalities }\end{array}$ & $\begin{array}{c}\text { Districts/Counties/ } \\
\text { County-Level } \\
\text { Cities }\end{array}$ & $\mathrm{X} 1$ & $\mathrm{X} 2$ & $\mathrm{X} 3$ & $\mathrm{X} 4$ & X5 & $\mathrm{X} 6$ \\
\hline \multirow[t]{7}{*}{ Fuzhou } & Fuqing City & 0.51 & 0.53 & 0.28 & 0.41 & 0.40 & 0.45 & \multirow[t]{7}{*}{ Longyan } & Liancheng County & 0.10 & 0.16 & 0.18 & 0.20 & 0.17 & 0.17 \\
\hline & Luoyuan County & 0.39 & 0.28 & 0.40 & 0.20 & 0.24 & 0.21 & & $\begin{array}{c}\text { Shanghang } \\
\text { County }\end{array}$ & 0.23 & 0.30 & 0.26 & 0.29 & 0.36 & 0.28 \\
\hline & Mawei District & 0.29 & 0.24 & 0.33 & 0.09 & 0.29 & 0.28 & & Xinluo District & 0.01 & 0.18 & 0.18 & 0.18 & 0.19 & 0.20 \\
\hline & Minqing County & 0.21 & 0.21 & 0.29 & 0.21 & 0.20 & 0.13 & & Yongding District & 0.23 & 0.13 & 0.09 & 0.18 & 0.17 & 0.17 \\
\hline & Pingtan County & 0.19 & 0.28 & 0.10 & 0.09 & 0.29 & 0.16 & & Zhangping City & 0.17 & 0.11 & 0.21 & 0.24 & 0.22 & 0.19 \\
\hline & Yongtai County & 0.13 & 0.11 & 0.17 & 0.11 & 0.04 & 0.03 & & $\begin{array}{c}\text { Changting } \\
\text { County }\end{array}$ & 0.07 & 0.17 & 0.06 & 0.20 & 0.21 & 0.23 \\
\hline & Changle District & 0.36 & 0.39 & 0.33 & 0.19 & 0.30 & 0.30 & & Wuping County & 0.18 & 0.17 & 0.18 & 0.17 & 0.20 & 0.22 \\
\hline \multirow[t]{8}{*}{ Ningde } & Fu'an City & 0.10 & 0.16 & 0.18 & 0.20 & 0.17 & 0.17 & \multirow[t]{10}{*}{ Sanming } & Datian County & 0.08 & 0.11 & 0.09 & 0.19 & 0.04 & 0.09 \\
\hline & Fuding City & 0.23 & 0.30 & 0.26 & 0.29 & 0.36 & 0.28 & & Jianning County & 0.19 & 0.19 & 0.33 & 0.22 & 0.19 & 0.2 \\
\hline & Gutian County & 0.01 & 0.18 & 0.18 & 0.18 & 0.19 & 0.20 & & Jiangle County & 0.28 & 0.20 & 0.28 & 0.22 & 0.26 & 0.21 \\
\hline & Jiaocheng District & 0.23 & 0.13 & 0.09 & 0.18 & 0.17 & 0.17 & & Mingxi County & 0.30 & 0.16 & 0.27 & 0.20 & 0.21 & 0.16 \\
\hline & Pingnan County & 0.17 & 0.11 & 0.21 & 0.24 & 0.22 & 0.19 & & Ninghua County & 0.20 & 0.28 & 0.23 & 0.28 & 0.30 & 0.17 \\
\hline & Shouning County & 0.07 & 0.17 & 0.06 & 0.20 & 0.21 & 0.23 & & Qingliu County & 0.20 & 0.21 & 0.36 & 0.21 & 0.29 & 0.22 \\
\hline & Xiapu County & 0.18 & 0.17 & 0.18 & 0.17 & 0.20 & 0.22 & & Sanyuan District & 0.26 & 0.13 & 0.30 & 0.16 & 0.20 & 0.21 \\
\hline & Zhouning County & 0.22 & 0.22 & 0.28 & 0.24 & 0.26 & 0.20 & & Yong'an City & 0.18 & 0.23 & 0.08 & 0.24 & 0.26 & 0.23 \\
\hline Putian & Xianyou County & 0.11 & 0.23 & 0.09 & 0.28 & 0.23 & 0.23 & & Youxi County & 0.16 & 0.20 & 0.11 & 0.29 & 0.10 & 0.17 \\
\hline \multirow{5}{*}{ Quanzhou } & Dehua County & 0.33 & 0.26 & 0.24 & 0.27 & 0.28 & 0.26 & & Sha County & 0.23 & 0.24 & 0.45 & 0.24 & 0.23 & 0.28 \\
\hline & Jinjiang City & 0.18 & 0.29 & 0.17 & 0.30 & 0.23 & 0.20 & \multirow[t]{4}{*}{ Nanping } & Guangze County & 0.22 & 0.22 & 0.28 & 0.24 & 0.26 & 0.2 \\
\hline & Nanle City & 0.24 & 0.19 & 0.20 & 0.21 & 0.21 & 0.16 & & Jian'ou City & 0.11 & 0.23 & 0.09 & 0.28 & 0.23 & 0.23 \\
\hline & Quangang District & 0.13 & 0.16 & 0.18 & 0.16 & 0.16 & 0.16 & & Jianyang District & 0.33 & 0.26 & 0.24 & 0.27 & 0.28 & 0.26 \\
\hline & Yongchun County & 0.11 & 0.13 & 0.19 & 0.27 & 0.20 & 0.21 & & Pucheng County & 0.18 & 0.29 & 0.17 & 0.30 & 0.23 & 0.2 \\
\hline \multirow[t]{10}{*}{ Zhangzhou } & Dongshan County & 0.01 & 0.04 & 0.05 & 0.10 & 0.09 & 0.07 & & $\begin{array}{c}\text { Shunchang } \\
\text { County }\end{array}$ & 0.24 & 0.19 & 0.20 & 0.21 & 0.21 & 0.16 \\
\hline & Longhai City & 0.24 & 0.25 & 0.22 & 0.23 & 0.26 & 0.21 & & Wuyishan City & 0.13 & 0.16 & 0.18 & 0.16 & 0.16 & 0.16 \\
\hline & Nanjing County & 0.23 & 0.22 & 0.13 & 0.19 & 0.08 & 0.23 & & Yanping District & 0.11 & 0.13 & 0.19 & 0.27 & 0.20 & 0.21 \\
\hline & Pinghe County & 0.08 & 0.10 & 0.04 & 0.13 & 0.03 & 0.10 & & Zhenghe County & 0.01 & 0.04 & 0.05 & 0.10 & 0.09 & 0.07 \\
\hline & $\begin{array}{l}\text { Xiangcheng } \\
\text { District }\end{array}$ & 0.08 & 0.19 & 0.21 & 0.07 & 0.21 & 0.19 & & & & & & & & \\
\hline & Yunxiao County & 0.03 & 0.03 & 0.04 & 0.01 & 0.01 & 0.02 & & & & & & & & \\
\hline & Zhangpu County & 0.10 & 0.13 & 0.11 & 0.20 & 0.16 & 0.11 & & & & & & & & \\
\hline & Changtai County & 0.30 & 0.33 & 0.17 & 0.24 & 0.17 & 0.26 & & & & & & & & \\
\hline & Zhao'an County & 0.03 & 0.03 & 0.04 & 0.05 & 0.10 & 0.01 & & & & & & & & \\
\hline & Hua'an County & 0.27 & 0.29 & 0.16 & 0.07 & 0.13 & 0.30 & & & & & & & & \\
\hline
\end{tabular}

To-be-transformed traditional villages were mainly affected by investment X2 (regional direct investment) and consumer market size X6 (total retail sales of consumer goods). Analysis of the $q$ value between industrial transformation and each factor with the geographical detector showed that X2 (0.29) and X6 (0.30) of Xianyou County, X2 (0.27) and X6 (0.29) of Zhao'an County, X2 (0.24) and X6 (0.28) of Mawei District, and X2 (0.26) and X6 (0.28) of Quangang District were subject to the greatest influence of X2 and X6. At the stage 
when industry remains to be transformed in traditional villages, enterprises grow rapidly in quantity, but incomplete industry types and indistinct leading industries are major problems that urgently need to be solved. In Shanhe Village of Zhangzhou, there were only 10 enterprises in service industry before 2009, but in 2009-2020, the number of enterprises climbed to 30, including 14 agricultural enterprises and 2 services enterprises with over RMB10 million investment. However, no enterprise in the secondary industry emerged. It can be seen that traditional villages that remain to be transformed are significantly affected by regional investment and consumer market size. The stronger the impact, the faster industry will develop and transform.

Transformed traditional villages were affected most by X4 (highway mileage) and X5 (scientific and technological expenditure). In the inland city Longyan, X4 (0.24) and X5 (0.22) of Zhangping City, X4 (0.17) and X5 (0.20) of Wuping County, and X4 (0.18) and X5 (0.19) of Xinluo District were most evidently subject to the effect of X4 and X5. At the stage when industry is transformed in traditional villages, primary, secondary, and tertiary industries develop in relative balance. In Zhongxin Village of Longyan, the first enterprise in financial services was set up in 1996, and by 2020, a total of 996 enterprises in tertiary industry had been established, covering multimodal transport and freight forwarding, commercial services, catering, road transportation, culture and art, education, research, and experimental development. Local traffic improvement and scientific and technological input promote exchanges and development of industries and will provide larger space for future industrial development.

\subsubsection{Difference in Influencing Factors for Coastal and Inland Areas}

Traditional villages in coastal and inland areas presented obvious differences in influencing factors for transformation. In coastal areas, economic factors such as economic development level (X1) and consumer market size (X3, X6) exerted main influence over industrial transformation of traditional villages, as indicated in Figure 6. Analysis of the $q$ value between industrial transformation and each factor with the geographical detector showed that counties mainly subject to the influence of X1 (GDP growth) included Nan'an City (0.58), Fuqing City (0.51), Zhao'an County (0.41), Luoyuan County (0.39), and Changle District (0.36); counties mainly under the impact of X3 (per capita GDP) included Luoyuan County (0.40), Quangang District (0.39), Mawei District (0.33), Changle District (0.33), and Minqing County (0.29); and counties under the dominant influence of X6 (total retail sales of consumer goods) included Nan'an City (0.53), Fuqing City (0.45), Changle District (0.30), Xianyou County (0.30), and Longhai City (0.30). Traditional villages in coastal areas are significantly affected by the fast-growing urban economy. Large investment, rapid population migration to urban areas, and higher per capita income for farmers have encouraged farmers to live and work in cities and townships, which further fuels the rapid industrial transformation and development in traditional villages. Moreover, all-out implementation of the Belt and Road initiative will offer more opportunities and create a larger market for traditional villages in the 14th Five-Year Plan period.

In inland areas, social factors including investment (X2), traffic accessibility (X4), and policy environment (X5) were main influencing factors for the industrial transformation in traditional villages. According to analysis of the $q$ value between industrial transformation and each factor with the geographical detector, X2 (regional direct investment) posed a dominant influence on such counties as Shanghang County (0.30), Pucheng County (0.29), Ninghua County (0.28), Jianyang District (0.26), Sha County (0.24), and Yong'an City (0.23); X4 (highway mileage) exerted main influence over Pucheng County (0.30), Shanghang County (0.29), Youxi County (0.29), Ninghua County (0.28), Jian'ou City (0.28), Jianyang District (0.27), and Yanping District (0.27); and X5 (scientific and technological expenditure) was the main influencing factor for Shanghang County (0.36), Ninghua County (0.30), Qingliu County (0.29), Jianyang District (0.28), Jiangle County (0.26), Yong'an City (0.26), and Guangze County (0.26). Inland traditional villages have far less economic appeal than economically developed coastal areas due to the poor consumption environment and back- 
ward economic development. However, after local governments increased investment in technology and local transportation accessibility, the rapid development of secondary and tertiary industry has driven the transformation of regional industries; therefore, hopefully the economic core of the inland regions will emerge. In this sense, inland areas should actively press ahead with rural industrial revitalization, preserve the value of traditional villages, and promote economic development [56].

Based on the analysis of different influencing factors at different transformation stages and in different locations, the influence mechanism of industrial transformation of traditional villages is proposed, as shown in Figure 7.

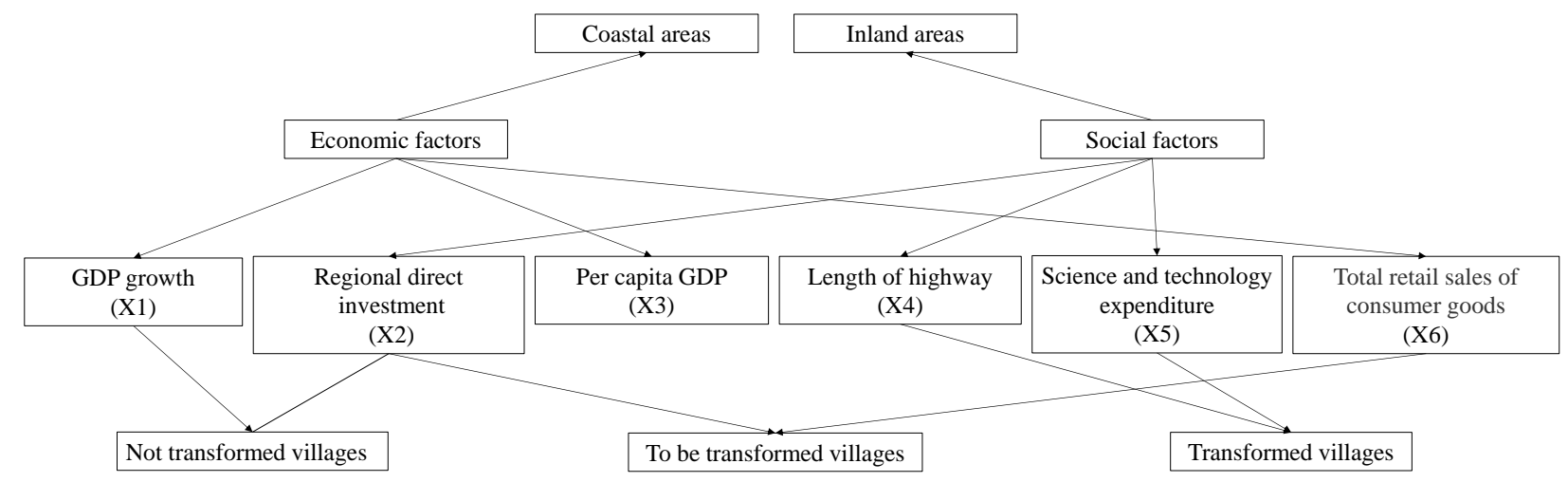

Figure 7. The influence mechanism of industrial transformation of traditional villages.

\section{Conclusions}

This study took the 211 national traditional villages in Fujian Province as its research object and used GIS spatial analysis and a geographical detector to analyze the spatial pattern and influence mechanism of industrial transformation in these villages. It came to the following conclusions.

(1) The industrial scale of traditional villages presented the characteristics of wavy growth. Temporally, at the critical times when the central government issued strategies for promoting rural development and revitalization, the number of traditional village enterprises would grow rapidly and reach a peak. Spatially, traditional village enterprises are mainly distributed in coastal areas, with high-density cluster areas in Pingnan and Zhouning counties of Ningde, Dehua County of Quanzhou, and Pinghe County of Zhangzhou and with medium-density cluster areas in Yongtai County of Fuzhou, Jiaocheng District of Ningde, and Jinjiang City of Quanzhou.

(2) There are multiple types of industrial transformation for traditional villages. The process of industrial transformation in traditional villages shows a trend of transitioning from the balanced development of the primary, secondary, and tertiary industries to the secondary and tertiary industries as the dominant industries. Temporally, at the early stage of industrial transformation, due to the lack of policy influence and financial input, many traditional villages were supported by no industry or a single industry composed of a few enterprises. At the middle stage, some traditional villages took part in rural revitalization, and these villages set up a large number of small-size enterprises in diversified industries but lacked a distinct dominant industry. Later, under the comprehensive influence of policies, a large number of enterprises of large size emerged in the villages, and dominant industries were noticeable. Traditional villages were categorized into not transformed, to-be-transformed, and transformed villages. The three stages of transformation presented different features of industry development. Not transformed villages are dominated by tertiary industry, especially retail. In villages that remain to be transformed, enterprises grow rapidly in quantity, but industries are not diversified enough in type and leading industries are not distinct. In villages that are transformed, secondary industry is the main 
driver of the economy, and processing and manufacturing are the major channels of industrial transformation.

(3) Influencing factors for industrial transformation in traditional villages included regional economic development level, consumer market size, policy environment, regional investment, and traffic accessibility. These influencing factors presented obvious differences at different transformation stages and in different locations. Temporally speaking, the main factors influencing industrial transformation for not transformed traditional villages include GDP growth and regional direct investment. As time goes on and the economy develops, influencing factors for to-be-transformed villages are regional direct investment and total retail sales of consumer goods. Eventually, highway mileage and scientific and technological expenditure evolve into the main influencing factors for transformed villages. In spatial distribution, influencing factors for coastal villages mainly include economic factors such as GDP growth, per capita GDP and total retail sales of consumer goods, while factors for inland villages are mainly social ones such as regional direct investment, highway mileage, and scientific and technological expenditure.

(4) This paper analyzed the evolution of traditional village industries from the spatial perspective. The research found that traditional villages can be categorized into three types, not transformed, to-be-transformed, and transformed villages. Traditional villages in coastal areas mainly fall into the categories of transformed and to-be-transformed villages. This categorization of traditional villages further improves the classification system of rural industry development model in social economics. Meanwhile, the results of geographical detector analysis showed that the three transformation types of traditional villages presented obvious differences in core influencing factors. Not transformed villages were mainly affected by GDP growth and regional direct investment, while transformed villages were mainly influenced by highway mileage and scientific and technological expenditure. These results deepen the research on the influence mechanism of industrial transformation in traditional villages. Finally, this research on traditional villages in Fujian province found that the industrial transformation and development of traditional villages has a large gap within the province. Only a few traditional villages have transformed into diversified industries or balance-developed villages. Most traditional villages fell into the categories of to-be-transformed or not transformed villages. This has important guiding value for the promotion of China's rural revitalization strategy.

\section{Implications and Limitations}

From the analysis of industrial pattern of traditional villages and the influence mechanism of industrial transformation, it can be seen that traditional villages are currently at a critical stage of transformation from primary and secondary industry to service industry. The rationalization and upgrading of the industrial structure is an urgent problem faced by traditional villages. Therefore, the findings of this study provide two practical implications.

First, the optimization of industrial structure is a prerequisite for the transformation and development of rural industries. Since the Chinese central government put forward the strategy of rural and industrial revitalization, local governments have issued corresponding policies to carry out this strategy in their local areas. However, the economic development level of various regions varies greatly, and not all regions have entered a fairly high stage of development. For example, for traditional villages with relatively backward economic development in the inland areas of Fujian Province, if the development strategies are excessively market-oriented, they will not only fail to bring economic benefits, but may also lead to malformed industrial development and induce "rural diseases", which can be very detrimental to economic and social development [57]. Therefore, local governments should formulate appropriate industrial adjustment and optimization policies based on local conditions to promote the rationalization of the local industrial structure. 
Second, the goal of the industrial transformation of traditional villages is to upgrade the industrial structure. At present, traditional villages in various regions are in different stages of industrial transformation. The leading factors affecting the industrial transformation of villages are obviously different. The backwardness of agricultural technology, the need to upgrade labor-intensive manufacturing, and the shortage of talents in high-end industries are urgent problems that villages need to solve in all stages of development. The optimization and upgrading of the industrial transformation of traditional villages should make full use of the interaction of multiple factors to formulate customized rural development policies to develop modern agriculture, new industrialization, and green industries. Industrial transformation should strive to improve the economic backwardness situation of traditional villages and upgrade rural industrial structure. In the meantime, it should strive to solve such "rural diseases" as the hollowing out and loss of traditional culture in traditional villages.

This study remains to be further improved in some areas. First, data about enterprises with registered addresses were acquired from the Fujian Provincial Enterprise Credit Database. However, in addition to enterprises with registered addresses in traditional villages, there are also many informal enterprises that contribute to the revitalization of rural industries. These enterprises are not registered in the Database and are not included in this study. Future study needs to obtain relevant information and information through on-site investigations and interviews. Second, this study constructed the evaluation index system and evaluated the industrial transformation and development of traditional villages on the small scale of the county. Under the premise of consistent and comparable indexes covering traditional villages in Fujian, this study is limited in selection of industrial transformation indexes due to the unavailability of statistics on the scale of the county and township. This is an area where improvements need be made in the future and an expedient measure in regard to the limited statistics that are available. Looking ahead, it is feasible to improve the index system by conducting field surveys to get first-hand index data and expand channels to the data source. It is also possible to quantitatively and qualitatively study cases of industrial transformation of different types in traditional villages to further deepen the research.

Author Contributions: M.L. (Mingshui Lin) designed and implemented the data analysis methods and wrote the manuscript. J.J. and Y.Z. supervised the data analysis, participated in writing, and revised the manuscript. H.Y. and M.L. (Menglung Lin) assisted with the data analysis and manuscript preparation. All authors have read and agreed to the published version of the manuscript.

Funding: This research was funded by a project of the National Natural Science Foundation of China (grant No. 41971261), the Major Program for the consultation of Fujian Provincial Development Research Center (grant No. 2021JCZX010), the Social Science Fund of Fujian province of China (grant No. FJ2021JHKP025), the Natural Science Foundation of Fujian province of China (grant No. 2019J01430), and the China Mindong Tourism Poverty Alleviation Research Center 2020 Open Project (grant No.EFTPARC202001).

Institutional Review Board Statement: Not applicable.

Informed Consent Statement: Informed consent was obtained from all subjects involved in the study.

Data Availability Statement: The data presented in this study are available on request from the corresponding author. The data are not publicly available because this study signed a confidentiality pledge with the respondents.

Conflicts of Interest: The authors declare no conflict of interest.

\section{References}

1. Portes, A.; Evans, P. Embedded autonomy: States and industrial transformation. Hisp. Am. Hist. Rev. 1995, 77, 365. [CrossRef]

2. Mao, Y. Technological Thoughts on Scientific and Technological Innovation Promoting Rural Rejuvenation. E3S Web Conf. 2021, 235, 02035. [CrossRef]

3. Yang, J.; Yang, R.; Chen, M.H.; Su, C.H.J.; Zhi, Y.; Xi, J. Effects of rural revitalization on rural tourism. J. Hosp. Tour. Manag. 2021, 47, 35-45. [CrossRef] 
4. Albert, P.; Bruce, J. Rural development and dynamic externalities in Taiwan's structural transformation. Econ. Dev. Cult. Chang. 2000, 44, 180-208.

5. Chen, A.; Scott, S. Rural development strategies and government roles in the development of farmers' cooperatives in China. J. Agric. Food Syst. Community Dev. 2014, 4, 35-55. [CrossRef]

6. Liu, Y.; Li, Y. Revitalize the world's countryside. Nature 2017, 548, 275-277. [CrossRef]

7. Liu, Y.; Zhang, Y.; Yang, Y. China's rural revitalization and development: Theory, technology and management. J. Geogr. Sci. 2020, 30, 1923-1942. [CrossRef]

8. Holmes, J. Impulses towards a multifunctional transition in rural Australia: Interpreting regional dynamics in landscapes, lifestyles and livelihoods. Landsc. Res. 2008, 33, 211-223. [CrossRef]

9. Holmes, J. Impulses towards a multifunctional transition in rural Australia: Gaps in the research agenda. J. Rural Stud. 2005, 22, 142-160. [CrossRef]

10. Ramniceanu, I.; RAckrill, R. EU rural development policy in the new member states: Promoting multifunctionality? J. Rural Stud. 2006, 23, 416-429. [CrossRef]

11. Chang, W.S.; Lee, Y.H. Policy momentum for the development of Taiwan's cultural creative industries. Curr. Issues Tour. 2014 18, 1088-1098. [CrossRef]

12. Zhang, D.; Gao, W.; Lv, Y. The Triple Logic and Choice Strategy of Rural Revitalization in the 70 Years since the Founding of the People's Republic of China, Based on the Perspective of Historical Evolution. Agriculture 2020, 10, 125. [CrossRef]

13. Cao, W.; Hu, Y.; Cao, C. The urbanization process should promote the conservation and development of traditional villages. Urban Dev. Stud. 2013, 21, 34-36.

14. Li, Y.H.; Yan, J.Y.; Wu, W.H.; Liu, Y.S. The process of rural transformation in the world and prospects of sustainable development. Prog. Geogr. 2018, 37, 627-635. [CrossRef]

15. Li, Y.; Wu, W.; Liu, Y. Land consolidation for rural sustainability in China: Practical reflections and policy implications. Land Use Policy 2018, 74, 137-141. [CrossRef]

16. Li, T.; Zhu, H.; Wang, Z. The cluster characteristics and structural model about rural tourism in South Jiangsu. Geogr. Res. 2020, 39, 2281-2294. [CrossRef]

17. Revitalizing the Rural Economy: The Power to Make a Change. Available online: https://www.ifpri.org/blog/revitalizing-ruraleconomy-power-make-change (accessed on 31 October 2019).

18. Liu, X. Exploring in the approach to rural revitalization in the view of green development. IOP Conf. Ser. Earth Environ. Sci. 2019, 310, 052074. [CrossRef]

19. Zheng, R.; Weng, Z.; Huang, J. Rural revitalization strategy: Urban-rural integration, factor allocation and institutional arrangements-The implementation of the rural revitalization strategy in the new era and the i-depth promotion of structural reform on the agricultural supply side summit summary. Agric. For. Econ. Manag. 2018, 1, 1-6.

20. Guo, X.; Zhang, K.; Yu, H.; Gao, J.; Zhou, X.; Su, Y. System awareness and road choice for the implementation of the rural revitalization strategy. Rural Econ. 2018, 1, 11-20.

21. Liu, Y.; Liu, Y.; Guo, L. Sofm-based functional subareas of rural area along the BohaiRim in China. Hum. Geogr. 2013, 28, 114-120. [CrossRef]

22. Tan, X.; An, Y.; Jiang, L. Spatial differentiation and formal mechanism of rural function types in Changsha-Zhuzhou-Xiangtan area. Econ. Geogr. 2018, 38, 80-88. [CrossRef]

23. Li, P.; Chen, W.; Sun, W. Spatial differentiation and influencing factors of rural territorial multifunctions in developed regions: A case study of Jiangsu province. Acta Geogr. Sin. 2014, 69, 797-807. [CrossRef]

24. Ge, D.; Zhou, L.; Long, H.; Qiao, W.; Li, Y. Types of agricultural production transformation and implications for rural vitalization: A case of the Huang-Huai-Hai Plain. Prog. Geogr. 2019, 38, 1329-1339. [CrossRef]

25. Sun, W.; Tian, X.; Yan, D.; Wu, J.; Wang, Y. A study of the spatial division pattern of rural industry: Taking the typical area of Nanjing metropolitan area as an example. Hum. Geogr. 2021, 36, 129-137. [CrossRef]

26. Lu, S.; Liu, Y.; Guan, X. Comprehensive Zoning of Agricultural Region Under the Rural-urban Development Transformation in China-A Case Study of Sampling Belt Along G106 in China. Sci. Geogr. Sin. 2013, 33, 909-917. [CrossRef]

27. Hong, H.; Xie, D.; Guo, L.; Hu, R.; Liao, H. Differentiation of spatial function in a mountainous rural area from a multi-functional perspective. Acta Ecol. Sinica 2017, 37, 2415-2427. [CrossRef]

28. Peng, J.; Liu, Z.; Liu, Y.; Chen, X.; Zhao, H. Assessment of farmland landscape multifunctionality at county level in Beijing-TianjinHebei area. Acta Ecol. Sinica 2016, 36, 2274-2285. [CrossRef]

29. Bański, J.; Stola, W. Transformation of the spatial and functional structure of rural areas in Poland. Rural Stud. 2002, 3, 1-12.

30. Holmes, J. Cape York Peninsula, Australia: A frontier region undergoing a multifunctional transition with indigenous engagement. J. Rural Stud. 2012, 28, 252-265. [CrossRef]

31. Luo, H. Analysis on the types of rural economy in the suburbs of big cities-A case study of Shanghai. J. Yunnan Norm. Univ. 1992, 4, 78-85. [CrossRef]

32. Song, Z.; Liu, L. Spatial Characteristics Analysis for Multifunctional Transition of Suburban Agricultural Areas in Beijing. Sci. Geogr. Sin. 2011, 31, 427-433. [CrossRef]

33. Fang, Y.; Liu, J. Diversified agriculture and rural development in China based on multifunction theory:Beyond modernization paradigm. Acta Geogr. Sin. 2015, 70, 257-270. [CrossRef] 
34. Wang, J.; Xu, C. Geodetector: Principle and prospective. Acta Geogr. Sin. 2017, 72, 116-134.

35. Liu, Y.; Yang, R. The Spatial Characteristics and Formation Mechanism of the County Urbanization in China. Acta Geogr. Sin. 2012, 67, 1011-1020. [CrossRef]

36. Chen, Y.; Wang, J.; Liu, S.; Shen, H.; Xu, W. The strategies in dealing with the manufacture of Jimei and Xinglin's Taiwanese investment zone under the financial crisis background. World Reg. Stud. 2010, 19, 111-122.

37. Wang, K.; Huang, Y.; Wang, X. The spatial path evolution of Taiwanese enterprises "Westward Advancement" from the perspective of rural industry revitalization: A case study of Fujian province (in Chinese). Geogr. Res. 2020, 39, 1104-1115. [CrossRef]

38. Yu, B.; Tang, Y.; Wei, Z.; Bi, L. Spatial-Temporal Heterogeneity Evolution and Simulation of Changsha Ecological Background Quality. Econ. Geogr. 2016, 36, 173-181. [CrossRef]

39. Chen, X.; Yu, T. Empirical Research on the Influence of Situ Urbanization on Regional Consumption Market. Econ. Geogr. 2015, 35, 80-86. [CrossRef]

40. Tonts, M.; Plummer, P.; Argent, N. Path dependence, resilience and the evolution of new rural economies: Perspectives from rural Western Australia. J. Rural Stud. 2014, 36, 362-375. [CrossRef]

41. Mitchell, C.; Madden, M. Re-thinking commercial counter-urbanization: Evidence from rural Nova Scotia, Canada. J. Rural Stud. 2014, 36, 137-148. [CrossRef]

42. Rashid, M.; Ngah, I.; Misnan, S. Revitalizing Rural Areas in Malaysia: A Framework for Economic Revitalization. IOP Conf. Ser. Earth Environ. Sci. 2019, 385, 012004. [CrossRef]

43. Gan, C.; Zheng, R.; Yu, D. An Empirical Study on the Effects of Industrial Structure on Economic Growth and Fluctuations in China. Econ. Res. J. 2011, 46, 4-16. [CrossRef]

44. Chen, B. Income inequality and consumption demand: Theory and evidence from China. Nankai Econ. Stud. 2012, 1, 33-49. [CrossRef]

45. Plazinić, B.R.; Jović, J. Women and transportation demands in rural Serbia. J. Rural Stud. 2014, 36, 207-218. [CrossRef]

46. Feldman, M.; Kelley, M. The extant assessment of knowledge spillovers: Government R\&D policies, economic incentives and private firm behavior. Res. Policy 2006, 10, 1509-1521. [CrossRef]

47. Li, Y.; Chen, C.; Wang, Y. Urban-rural transformation and farmland conversion in China: The application of the environmental Kuznets Curve. J. Rural Stud. 2014, 36, 311-317. [CrossRef]

48. Lin, M.; Lin, J.; Lin, C.; Zhang, A.; Wang, K. Spatial diffusion of Taiwan enterprises in Mainland China under the vision of rural industrial vitalization. Sustainability 2018, 10, 3672. [CrossRef]

49. Teilmann, K. Measuring social capital accumulation in rural development. J. Rural Stud. 2012, 28, 458-465. [CrossRef]

50. Lin, M.; Lin, J.; Cheng, Y.; Wang, X.; Qi, X. Ecological vulnerability assessment of key villages of tourism poverty alleviation in Fujian Province. Acta Ecol. Sin. 2018, 38, 7093-7101. [CrossRef]

51. Head, L. Cultural ecology: Adaptation retrofitting a concept? Prog. Hum. Geogr. 2010, 34, 234-242. [CrossRef]

52. Head, L.; Atchison, J. Cultural ecology: Emerging human-plant geographies. Prog. Hum. Geogr. 2008, 33, 236-245. [CrossRef]

53. Sutton, M.; Anderson, E. Introduction to Cultural Ecology, 3rd ed.; Alta Mira Press: Lanham, MD, USA, $2014 ;$ pp. 12-34.

54. Lin, M.; Yan, Y.; Zeng, C.; Zhu, H.; Wang, F. Research on the Integration and Development of Red Tourism Resources in the Central Soviet Area from the Perspective of Cultural Ecology. J. Nat. Resour. 2021, 36, 1734-1748. [CrossRef]

55. Li, Y. On industrialization and urbanization in peri-urbanized rural areas. Urban Dev. Stud. 2017, 24, 89-94, CNKI:SUN:CSFY.0.2017-03-013.

56. Liu, C.; Lin, M.; Qi, X.; Zheng, W. Estimating the Preservation Value of Wuyishan National Park from the Perspective of Bounded Rational Decision Making. Sustainability 2021, 13, 6983. [CrossRef]

57. Guo, Y.; Yang, J.; Cao, B. The Evolution Course, Characteristics, Problems and Countermeasures of China's Rural Industrial Structure since the Founding of New China. Issues Agric. Econ. 2019, 4, 24-35. [CrossRef] 